\title{
La liturgie, entre mystère et pastorale
}

Université de Bourgogne, 4 février 2004

\section{Vincent Tabbagh}

\section{(2) OpenEdition}

Journals

Édition électronique

URL : https://journals.openedition.org/cem/946

DOI : $10.4000 /$ cem.946

ISSN : 1954-3093

Éditeur

Centre d'études médiévales Saint-Germain d'Auxerre

Édition imprimée

Date de publication : 15 août 2004

ISSN : 1623-5770

Référence électronique

Vincent Tabbagh, «La liturgie, entre mystère et pastorale », Bulletin du centre d'études médiévales d'Auxerre / BUCEMA [En ligne], 8 | 2004, mis en ligne le 21 décembre 2006, consulté le 22 septembre 2022. URL : http://journals.openedition.org/cem/946 ; DOI : https://doi.org/10.4000/cem.946

Ce document a été généré automatiquement le 22 septembre 2022.

\section{c) (i) (2)}

Creative Commons - Attribution - Pas d'Utilisation Commerciale - Partage dans les Mêmes Conditions 4.0 International - CC BY-NC-SA 4.0

https://creativecommons.org/licenses/by-nc-sa/4.0/ 


\section{La liturgie, entre mystère et pastorale}

Université de Bourgogne, 4 février 2004

\section{Vincent Tabbagh}

1 Par rapport à d'autres thématiques qui ont permis les renouvellements récents de l'histoire religieuse de la période $\mathrm{XI}^{\mathrm{e}}-\mathrm{XV}^{\mathrm{e}}$ siècles, comme la prédication, le culte des saints, ou la mémoire des morts, la liturgie apparaît encore quelque peu délaissée, ou abordée surtout par sa périphérie, les processions, le théâtre religieux, le chant et les livres liturgiques dans leur matérialité, les fêtes de dérision, l'architecture et l'aménagement des espaces, etc. Il semble donc que s'impose aujourd'hui la nécessité d'attaques plus frontales, par la mise en évidence d'évolutions, la construction de classifications par contenu (heures canoniales, messe, prière pour les morts, liturgies sacramentelles) ou par cadre et lieu de déploiement des rites (les gestes liturgiques seraient-ils identiques dans les communautés cléricales, les paroisses, les chapelles privées, les rassemblements de foules ?). Le repérage des caractères propres à la liturgie des différents ordres religieux devra être mené à bien. Le mobilier et les dispositifs, les vêtements, les vases sacrés, dans la ligne des études récentes sur le luminaire, constituent des territoires dont l'exploitation devrait révéler toute la richesse. Les communications et les échanges de la réunion du 4 février 2004 à l'Université de Bourgogne n'avaient pas d'autres buts que de mesurer l'ampleur et l'intérêt des nombreuses questions à ce jour largement sans réponses.

Eliana Magnani présente une étude de la cérémonie des mandés du jeudi saint à Cluny, d'après les quatre coutumiers du XI ${ }^{e}$ siècle, en particulier le plus récent, celui du moine Bernard. Un double lavement des pieds concerne les moines et les pauvres. Ces derniers, en nombre égal à celui des frères, sont accueillis pour la circonstance à l'intérieur du monastère ; ils assistent d'abord à une messe, où ils reçoivent des hosties non consacrées, puis sont nourris et lavés une première fois par les serviteurs de l'abbaye, avant la cérémonie elle-même. Après le repas de la mi-journée, chaque frère baigne, dans le cloître, les pieds de son pauvre, avec de l'eau chaude, l'abbé accomplissant ce geste pour certains d'entre eux, en surnombre, qui représentent 
symboliquement les amis et familiers de la communauté qu'il a tenu à y associer. Les pauvres reçoivent alors du vin béni et une somme d'argent. Le mandé des frères se déroule ensuite, dans le chapitre, l'abbé lavant les pieds des moines, dans une reproduction précise de la scène décrite par l'évangile de Jean, dont le texte est chanté en même temps ; le terme mandatum a d'ailleurs été tiré de ce passage. Le déplacement des rôles des divers acteurs, exigé par la liturgie, se révèle d'une grande richesse spirituelle et symbolique : chacun à son tour incarne le Christ, à la fois maitre et serviteur, en se faisant pauvre et frère de chacun.

3 Pour se situer au croisement de la prière privée et de la liturgie, Alain Rauwel s'est intéressé aux oraisons personnelles des fidèles lors de l'élévation, dont de nombreux exemples figurent dans les livres d'Heures. Il démontre, exemples précis à l'appui, qu'elles remontent beaucoup plus haut que le $\mathrm{XV}^{\mathrm{e}}$ siècle auquel on les attribue généralement. Elles apparaissent en fait au même moment que l'élévation de l'hostie elle-même, donc vers 1200. Un manuel de liturgie de Pierre de Roissy, chancelier de Chartes, vers 1210, cite une prière qu'il attribue à "P., chancelier de Paris". Ce texte circule ensuite, depuis une règle en langue vernaculaire destinée à des recluses anglaises de la fin du XII ${ }^{e}$ siècle jusqu'aux livres d'Heures du XV', avec de modestes variantes. Surtout, d'après une Vita de saint Thomás, c'est elle que le savant dominicain prononce à l'article de la mort, en recevant le viatique. D'autres formules ont circulé dans le milieu franciscain, à partir de la Somme de théologie d'Alexandre de Halès. Cette dévotion verbalisée à l'eucharistie a donc pris naissance dans le milieu des maîtres de l'Université. Par la suite, plusieurs types de prières apparaissent, y compris dans des chaînes à réciter depuis l'élévation jusqu'à la communion, en langue vernaculaire ou en latin, certaines très proches des énoncés liturgiques du canon, ce qui permet donc au fidèle de prononcer les mêmes paroles que le prêtre, les phrases de la consécration exclues, évidemment. Le fidèle se trouve ainsi à même de s'approprier ce qui est devenu l'acte premier de la liturgie.

4 Les "minutes cartusiennes" de Jean-Vincent Jourd'heuil montrent le dépouillement total et l'extrême rigueur des systèmes de clôture soigneusement maintenus par cet ordre. Dans l'église du monastère, où la communauté ne se réunit que le dimanche, les convers ne peuvent pénétrer ni même voir le chœur des moines. Leur demande ayant été entendue, un guichet s'ouvre, à partir de la fin du XIII ${ }^{\mathrm{e}}$ siècle, pour l'élévation, puis un peu plus tard, la porte au milieu de la clôture entre le chœur et la nef. La messe n'est jamais dite que par un prêtre assisté d'un diacre. Les corps morts n'entrent jamais dans le chœur. Les Chartreux sont bien restés des ermites pour lesquels la prière personnelle joue le rôle premier dans la sanctification. La messe, rarement célébrée, garde un caractère de mystère fortement affirmé.

5 Partant de l'exemple des sanctuaires bourguignons, Laurent Durnecker étudie la visibilité des reliques des saints. En interdisant de les toucher, Latran IV a opéré un transfert de vénération vers la vue, et apparaissent donc les reliquaires adaptés à cette démarche, comportant des fenêtres. Le culte des reliques et celui de l'eucharistie s'influencent mutuellement ; on rencontre des monstrances pour l'ostensión de l'hostie dès le XIV siècle. Le reliquaire cache et montre à la fois ; il est lui-même l'objet de stratégies de dissimulation et d'exhibition : conservé dans le trésor, il n'est exposé que lors des fêtes du saint, dans un dispositif qui vise sans doute à reporter sur lui la sacralité de la relique elle-même. Lorsque la châsse est visible en permanence, par sa disposition au-dessus de l'autel par exemple, elle dissimule complètement le corps 
qu'elle contient et son décor seul s'offre à la vue des fidèles. Dans ce cas, l'image, souvent complexe, retraçant par exemple l'histoire du saint, vient remplacer la relique, et à travers elle une dimension pastorale peut se développer, pour guider le fidèle vers des contenus spirituels et parfois même dogmatiques plus élaborés. Partie de ce reliquaire, l'image du saint se développe librement dans de multiples présentations, statues, tentures figurant sa vie. Elles envahissent l'espace sacré autour des reliques, autels, chapelles et chœurs, celui de la cathédrale de Langres avec les tapisseries de la vie de saint Mammès offertes par le cardinal de Givry par exemple, participant ainsi à sa sanctification.

Delphine Lannaud aborde ensuite la question délicate des jubés en Bourgogne, soulignant la difficulté des définitions et la rareté des vestiges monumentaux ou archivistiques. Le terme lui-même n'apparaît cependant qu'au $\mathrm{XV}^{\mathrm{e}}$ siècle, qui marque, avec celui qui suit, l'apogée de ce type de construction (Beaune, Autun, Flavigny, etc.). Auparavant, il s'agit plutôt de tribunes latérales séparées par un large espace libre, jubés discontinus en quelque sorte. La construction est plus ou moins close, monumentale en tout cas, fermant le chœur de la nef et prolongée sur les côtés par des éléments qui entourent complètement celui-ci. Elle s'installe aussi dans les églises paroissiales, édifiée alors en bois. Elle comporte toujours à son sommet une plate-forme avec coursière, et un crucifix. Le jubé semble d'abord un obstacle matériel destiné à protéger le chœur et à marquer, par une dimension de mystère, sa sacralité. Il a des fonctions liturgiques certaines mais finalement mal connues, de lecture, de proclamations, à son sommet, de célébrations à sa base qui comporte souvent, du côté de la nef, des autels. Pendant l'élévation, la porte au centre du jubé s'ouvre. Dans la discussion qui suit apparaît l'idée que cet édifice sert aussi la réaffirmation d'une situation éminente du clergé par rapport au développement des initiatives spirituelles des fidèles.

7 Esquissant une brève synthèse, Vincent Tabbagh note d'abord que la dimension pastorale paraît largement absente de la liturgie. Le sermon, significativement, s'est progressivement détaché d'elle. Les rites constituent d'abord la célébration d'un mystère, par imitation du culte rendu à Dieu dans le ciel par les anges et les bienheureux, dans une tradition fortement vétéro-testamentaire (chant des psaumes, chœur impénétrable assimilé au Saint des Saints) et dans une dimension à laquelle les communautés de clercs sont les premières sensibles, en utilisant subtilement l'alternance du secret et de l'ostensión. Mais la liturgie s'inscrit aussi dans la religion civique, par des cérémonies destinées à manifester l'ordonnance hiérarchisée de la communauté ecclésiastique et des espaces sacrés : éléments mobiliers comme les autels, gestes, vêtements, déplacements et paroles obéissent à des interdits et des monopoles qui doivent la rendre présente. À partir du XIII ${ }^{\mathrm{e}}$ siècle, cependant, un élément hétérogène pénètre peu à peu : la dévotion, attitude intérieure libre que Thomás d'Aquin oppose au culte public rendu à Dieu. Elle inspire les tentatives de réforme des comportements liturgiques du clergé qui fleurissent ici ou là, en particulier au XV siècle, s'efforçant d'établir des synthèses entre l'extériorité objective des rituels et l'approfondissement de la relation personnelle à Dieu. Comme celle-ci trouve mieux à s'exprimer dans le développement de la prière domestique, discordances et contradictions viennent parfois affaiblir la lisibilité et la richesse symbolique d'une liturgie qui disparaît presque complètement des pratiques de courants réformés au $\mathrm{XVI}^{\mathrm{e}}$ siècle. 
INDEX

Mots-clés : liturgie 